\title{
Modeling Blue and Green Water Resources Availability in an Iranian Data Scarce Watershed Using SWAT
}

\author{
Gholamabbas Sayyad, ${ }^{1,2}$ Lida Vasel, ${ }^{2}$ Ali Asghar Besalatpour, ${ }^{3}$ Bahram Gharabaghi ${ }^{4}$ and Golmar \\ Golmohammadi ${ }^{4}$ \\ ${ }^{1}$ Trent University, Peterborough, Ontario; ${ }^{2}$ Shahid Chamran University of Ahvaz, Ahvaz, Iran; $\quad{ }^{3}$ Vali-e-Asr University of Rafsanjan, Rafsanjan, \\ Iran; $\quad{ }^{4}$ University of Guelph, Guelph, Ontario.
}

Received 2015-04-25, accepted 2015-07-28, published 2015-11-05.

\begin{abstract}
Knowledge of the renewable water resources of a watershed is strategic information which is vital for the long term planning of water and food security. In this study, we used a Soil and Water Assessment Tool (SWAT) model in combination with the sequential uncertainty fitting algorithm (SUFI-2) to simulate the water resource components (blue and green water) in the data scarce Kohnak watershed (in southwest Iran) based on river discharges. The simulation was performed for the period from 1992 to 2009 by considering the first three years as warm up. Due to imperfect incomplete climate data, two solution methods, (1) combining CRU data with observed climate data, and (2) integrating expert knowledge in defining uncertainty parameter ranges in the calibrating period, were used to increase the model accuracy prediction. Sensitivity and uncertainty analyses were also performed to improve the model performance. Simulated water resources components of blue water flow, green water storage, and green water flow were evaluated at the subbasin scale. The results showed that with the applied solution methods, SWAT could satisfactorily predict discharge flows and water resource components in the Kohnak watershed. The spatial variabilities of blue and green waters were a function of the spatial variability of precipitation, soil depth, land cover type and slope. Both the blue and green water flows decreased from upstream to downstream. The green water storage was larger in the middle and lower subbasin. It indicates that these regions have relatively sufficient precipitation and green water resources, which are beneficial for the development of rain fed agriculture. This study showed that in data scarce watersheds, a SWAT model in combination with expert knowledge can be used as a suitable tool for water component prediction.
\end{abstract}

\section{Introduction}

Quantifying available water resources for natural ecosystem and society is one of the most important objectives for hydrologists. Renewable freshwater is the foundation for life in terrestrial and freshwater ecosystems (Jackson et al. 2001). The concepts of blue water and green water were first defined by Falkenmark (1995) and developed by others. Blue water flow is the sum of surface water and deep aquifer recharge. Green water flow is the actual evapotranspiration (AET) released to the atmosphere through a combination of evaporation from soil and water bodies and transpiration from vegetation. The green water storage (soil moisture) is the amount of water in the soil profile at the end of a time period (Falkenmark and Rockström 2006). At a global level, about $65 \%$ of water received as precipitation returns to the atmosphere as green water flow (i.e. transpiration from forest, grassland, wetlands and rainfed farmlands). Water resources availability and assessing the blue and green water distribution can be useful for water resources management and planning. In Iran, irrigated agriculture uses $>90 \%$ total water usage and $\sim 60 \%$ total renewable water resources (Alizadeh and Keshavarz 2005; Keshavarz et al. 2005). Therefore it is important to obtain more realistic information on water resources availability and quantifying the blue and green water flows as well as green water storage in individual watersheds and the whole country.

There have been many studies quantifying the green and blue water resources since the advent of the concept (Gerten et al. 2005; Guodong and Wenzhi 2006; Schuol et al. 2008; Faramarzi et al. 2009; Zang et al. 2013; Kiptala et al. 2014). Hydrologic models, which are powerful tools for simulating hydrological processes and assessing water resources, can provide more insights into the mechanisms of land surface and hydrological processes. Among the hydrologic models, the Soil and Water Assessment Tool (SWAT) is one of that can be used to simulate green and blue water flow for the watersheds. SWAT is a conceptual, physically

Sayyad, Gholamabbas, Lida Vasel, Ali Asghar Besalatpour, Bahram Gharabaghi and Golmar Golmohammadi. 2015. "Modeling Blue and Green Water Resources Availability in an Iranian Data Scarce Watershed Using SWAT." Journal of Water Management Modeling C391. doi:10.14796/JWMM.C391 (c) CHI 2015. www.chijournal.org ISSN 2292-6062. 
based, continuous model. It operates on a daily time step and is designed to predict the impact of watershed management practices on hydrology, sediment and water quality on a gauged or an ungauged watershed. The major model components include weather generation, hydrology, sediment, crop growth, nutrient and pesticide subroutines (Arnold et al. 1998). To accurately simulate water quality and quantity, SWAT requires specific information about topography, weather (precipitation, temperature), hydrography (groundwater reserves, channel routing, ponds or reservoirs, sedimentation patterns), soil properties (composition, moisture and nutrient content, temperature, erosion potential), crops, vegetation, and agronomic practices (tillage, fertilisation, pest control) (Neitsch et al. 2011). Faramarzi et al. (2009) adopted a SWAT model to simulate the blue and green water resources in Iran and the impacts of different irrigation practices on the water balances of areas with irrigated agriculture were discussed in this study. They suggested using the same modeling approach for the high resolution analysis of water resources in arid and semi-arid areas. Schuol et al. (2008) used SWAT to simulate green and blue water resources in Africa and the results were satisfactory, although high uncertainties were observed in some subbasins.

The decisions for balancing green and blue water for food, nature and society will be necessary to improve the water resources planning and management, especially for developing countries, where the totality of global population growth and malnourishment is essentially concentrated (Falkenmark and Rockström 2006).

The main objectives of this research were: to calibrate and validate a hydrologic model for the Kohnak watershed with a scarce dataset located in south west of Iran; to evaluate the effect of integrating CRU data and expert knowledge in calibrating on model accuracy prediction; and to estimate the blue and green water at the subbasin level. In order to satisfy the objectives of this study, a SWAT model in combination with the Sequential Uncertainty Fitting program (SUF-2) (Abbaspour 2011) were selected for the calibration and uncertainty analysis and also to estimate the blue and green water hydrologic components.

\section{Methodology}

\subsection{Study Area}

Kohnak watershed with a total drainage area of $1140 \mathrm{~km}^{2}$ is located in the province of Khuzestan, Southern Iran. It lies between latitudes $32^{\circ} 03^{\prime} \mathrm{N}$ and $32^{\circ} 39^{\prime} \mathrm{N}$ and longitudes $48^{\circ} 28^{\prime} \mathrm{W}$ and $48^{\circ} 55^{\prime} \mathrm{W}$ (Figure 1). This watershed is a tributary of the Dez River basin the northern part of the Karun-Dez watershed, the largest basin of Iran. The major river in the watershed is the Kohnak river. The long term average rainfall and temperature ranges in the region are $383 \mathrm{~mm}$ and $23.5^{\circ} \mathrm{C}$ respectively. The average elevation is $1809 \mathrm{~m}$. Soil depth is $<5 \mathrm{~cm}$ in the steep areas and as deep as $150 \mathrm{~cm}$ in the lowlands. The soil textural classes are mainly silty loam and silty clay loam. The main land uses are deciduous forest at the northern part and rainfed and irrigated cropping systems in the southern parts.

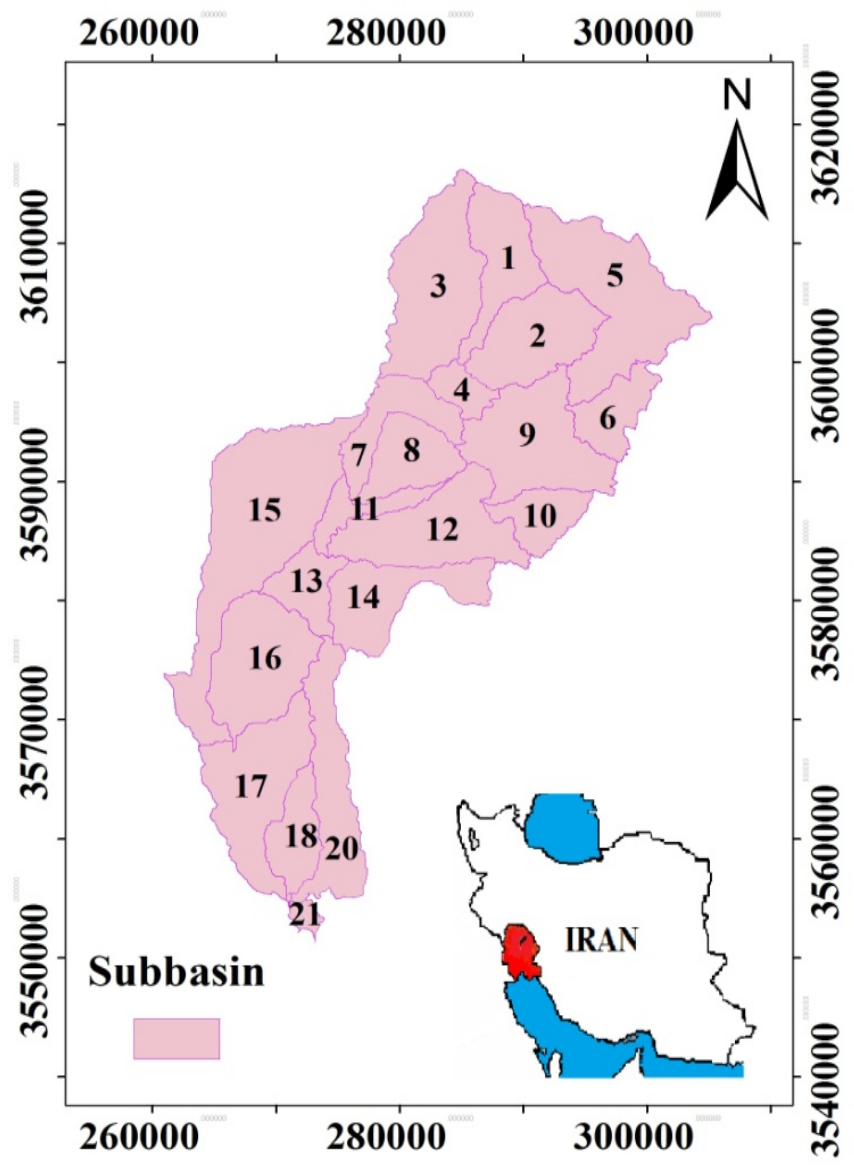

Figure 1 Location of Kohnak watershed and its subbasins in southern Iran.

\subsection{SWAT Model}

SWAT is open source software and provides the capability to analyse data on a daily, monthly and yearly basis (Kalogeropoulos and Chalkias 2012). A SWAT model is a watershed scale model for predicting the long term impacts of land management on water, sediments, and agricultural chemical yields in large complex un-gauged basins with varying soils, land use, and management conditions (Arnold et al. 1998; Gul and Rosbjerg 2009; Besalatpour et al. 2012; Khoi and Suetsugi 2012). It is a physically based, conceptual, continuous-time river basin model that operates on a daily time step (Neitsch et al. 2011). The hydrology of the model is based on the water balance equation in the soil profile where the processes simulated include precipitation, infiltration, surface runoff, evapotranspiration, lateral flow and percolation (Bouraoui et al. 2005). It integrates all relevant eco-hydrological processes including water flow, nutrient transport and turnover, vegetation growth, and land use and water management at the subbasin scale. The area of study is subdivided into a number of subbasins, which are characterized by one or more hydrologic response 
units (HRUs) such that each consists of homogeneous land use, management and soil characteristics. HRUs are the spatial units where the vertical flows of water and nutrients are calculated, which are then aggregated and summed for each subbasin. Runoff, sediments and chemicals are simulated for each HRU and then aggregated for the subbasin, and routed to the watershed outlet. Furthermore, water flow is routed through the channel network using the variable storage routing method or the Muskingum routing method (Arnold et al. 1998; Neitsch et al. 2011; Khoi and Suetsugi 2012; Kalogeropoulos and Chalkias 2012).

$\mathrm{HRU}$ water balance is represented by four storage volumes including snow, soil profile (0 $\mathrm{m}$ to $2 \mathrm{~m}$ ), shallow aquifer (typically $2 \mathrm{~m}$ to $20 \mathrm{~m}$ ), and deep aquifer (>20 m) (Arnold et al. 1998). SWAT calculates peak runoff rate with a modified rational method (Chow et al. 1988). Soil water processes include evaporation, surface runoff, infiltration, plant uptake, lateral flow, and percolation to lower layers (Neitsch et al. 2011). Lateral flow, which occurs when the storage in any layer exceeds field capacity after percolation, is predicted with kinematics storage routing that is based on the degree of slope, slope length, and saturated hydraulic conductivity in each soil layer (Arnold et al. 1998).

Groundwater flow contribution to total stream flow is simulated by creating shallow aquifer storage (Arnold and Allen 1996). Percolation from the bottom of the root zone is considered as recharge to the shallow aquifer. To estimate potential evapotranspiration, three different methods including the Hargreaves method, the Priestley-Taylor method, and the Penman-Monteith method may be used (Arnold et al. 1998).

Sediment yield is estimated by the modified soil loss equation (MUSLE) model developed by Williams and Brendt in 1977 (Neitsch et al. 2011). The crop model used by SWAT is a simplification of the erosion-productivity impact calculator (EPIC) model that is based on daily accumulated heat units, the harvest index (HI), and above ground biomass (Arnold et al. 1998).

\subsection{Input Data and Model Setup}

The basic input data to SWAT are a digital elevation model (DEM), stream network coverage, land use, soil map, and climate data. A DEM with grid size of $10 \mathrm{~m} \times 10 \mathrm{~m}$ was used in this study. Stream network creation was done in the environment of ArcGIS using the DEM map. Soil data including sand, silt and clay contents, rock fragment content, organic carbon content, soil electrical conductivity (ECe), water content, porosity, bulk density, saturated hydraulic conductivity (Ks), and soil hydrologic groups were obtained by studying soil profiles in the main landscape subunits. Climate data, including daily rainfall and temperature values, were obtained from the precipitation and air temperature stations in the study for a period of $17 \mathrm{y}$ (1992 to 2009). Due to the imperfect and incomplete observed climate data, the obtained results were not good. Therefore for increasing the model accuracy, CRU (Climate Research Unit, http://www.cru.uea.ac.uk/) gridded climate data were combined with observed data. Abbaspour et al. $(2010 ; 2015)$ also got good results using CRU data. However

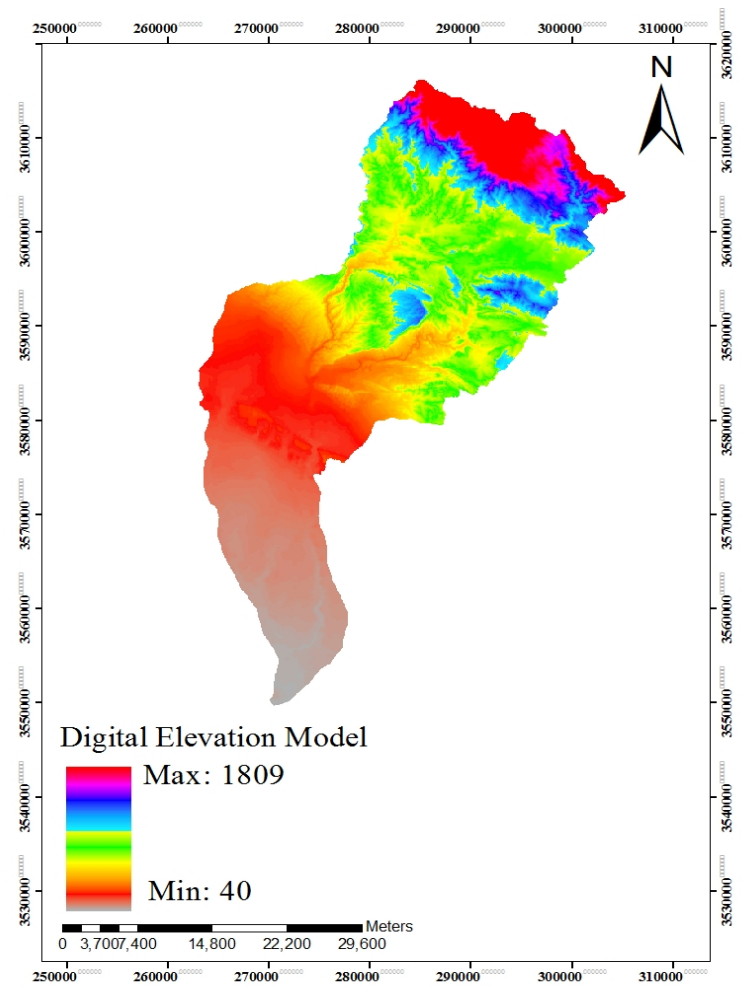

Figure 2a DEM input map for SWAT model.

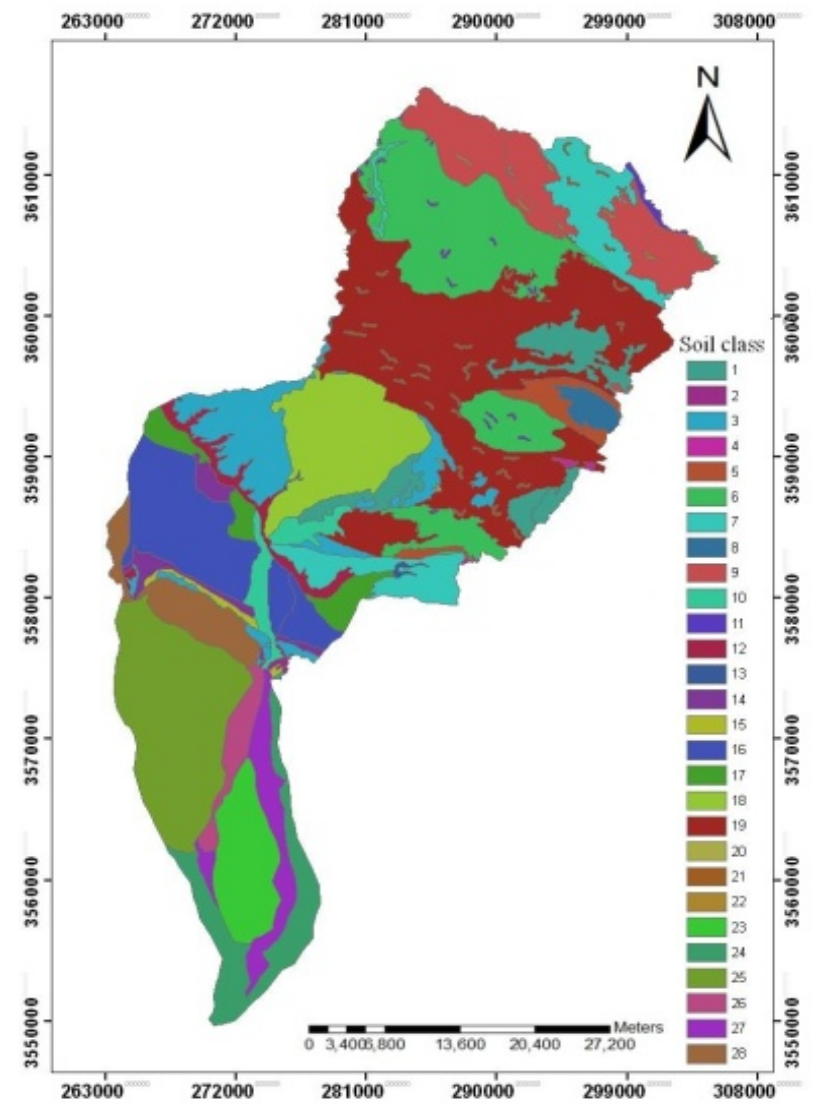

Figure 2b Soil input map for SWAT model. 


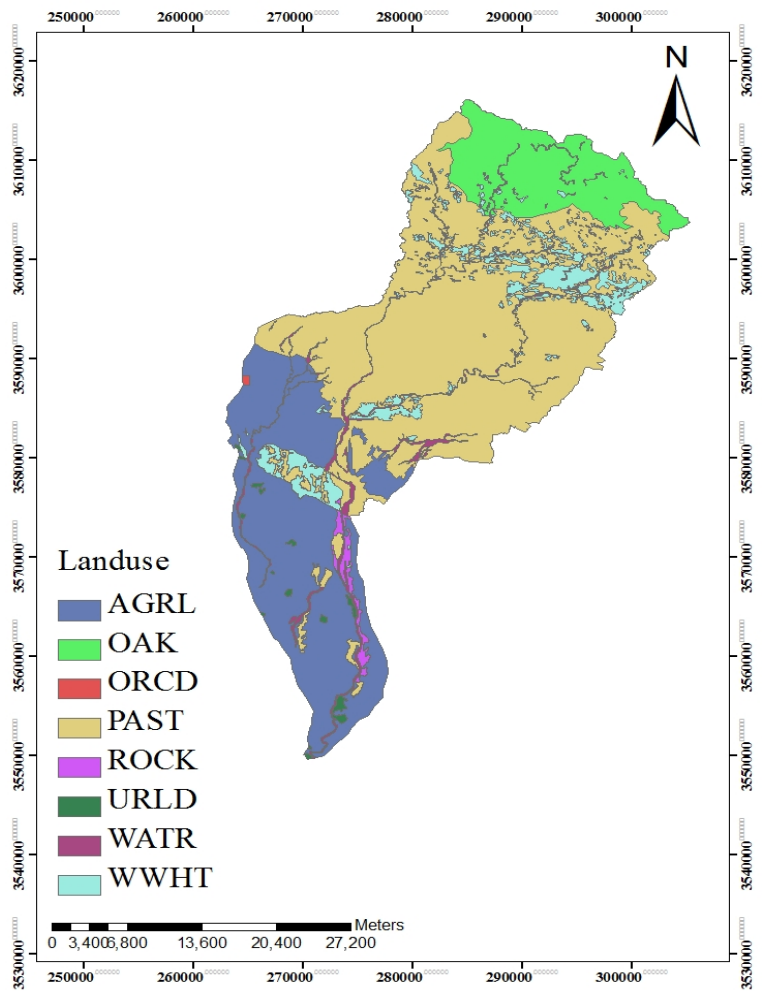

Figure 2c Land use input map for SWAT model.

in this study the combination of regional climate data and CRU data gave better model prediction. CRU data are long term daily data with no missing values.

Figures 2a, 2b and 2c (above) show the input maps (DEM, soil, and land use) to SWAT. In this study, surface runoff volume was estimated using a modified version of the Soil Conservation Service (SCS) curve number (CN) method (USDA-SCS 1972). The Muskingum method was used to compute the channel flood routing to the outlet of the watershed. The amount of evapotranspiration was calculated using the Hargreaves method.

\subsection{Sensitivity Analysis, Calibration and Valida- tion}

In this study, various SWAT parameters related to discharge and sediment were estimated using the SUFI-2 algorithm that is present in the SWAT-CUP2 software (Abbaspour 2011). In SUFI-2, parameter uncertainty accounts for all sources of uncertainties such as uncertainty in driving variables (e.g. rainfall), conceptual model, parameters, and measured data (Abbaspour 2011). The degree to which all uncertainties are accounted for is quantified by measure referred to as the $\mathrm{p}$-factor, which is the percentage of measured data bracketed by the $95 \%$ prediction uncertainty (95PPU). The 95PPU is calculated at the $2.5 \%$ and $97.5 \%$ levels of the cumulative distribution of an output variable obtained through Latin hypercube sampling, disallowing $5 \%$ of the very bad simulations. As all forms of uncertainties are reflected in the measured variables (e.g. discharge), the parameter uncertainties generating the 95PPU account for all uncertainties (Abbaspour 2011).

The SUFI-2 model starts by assuming a large parameter uncertainty (within a physically meaningful range), so that the measured data initially fall within the 95PPU. Then the uncertainty decreases in steps while monitoring the $p$-factor and the $d$-factor. The $d$-factor captures the goodness of calibration, as a smaller 95PPU band indicates a better calibration result. The $d$-factor is the ratio of the average distance between the above percentiles and the standard deviation of the corresponding measured variable. A value $<1$ is a desirable measure for the $d$-factor. Theoretically, the value for $p$-factor ranges between 0 and 100\% (an ideal situation would lead to a $p$-factor approaching 100\%). The degree to which the values deviate from these numbers can be used to judge the strength of the calibration (Abbaspour 2011).

An initial sensitivity analysis was done to determine sensitive parameters among the input parameters selected for calibration of the SWAT models (Table 1). The data for the period 2000 to 2009 were used to calibrate the model and the remaining five years of data (1995 to 1999) were used to validate the model.

Table 1 Selected input parameters for the calibration process.

\begin{tabular}{|c|c|c|c|}
\hline \multirow{2}{*}{ Name } & \multirow{2}{*}{ Definition } & \multicolumn{2}{|c|}{ Range } \\
\hline & & Min & Max \\
\hline r_CN2.mgt & SCS runoff curve number & -0.4 & 0.4 \\
\hline r-SOL_BD.sol & Soil bulk density $(\mathrm{g} / \mathrm{cm})$ & -0.4 & 0.4 \\
\hline r_SOL_AWC.sol & $\begin{array}{l}\text { Soil available water storage capacity } \\
\text { (mm water/mm soil) }\end{array}$ & -0.5 & 0.5 \\
\hline r_SOL_K.sol & Soil hydraulic conductivity ( $\mathrm{mm} / \mathrm{h})$ & -0.8 & 0.8 \\
\hline V_GW_DELAY.gW & Groundwater delay time (d) & 0 & 400 \\
\hline V_GWQMN.gW & $\begin{array}{l}\text { Threshold depth of water in the shallow aquifer required } \\
\text { for return flow to occur (mm) }\end{array}$ & 0 & 500 \\
\hline V_EPCO.hru & Plant uptake compensation factor & 0.01 & 1 \\
\hline v_ESCO.hru & Soil evaporation compensation factor & 0.01 & 1 \\
\hline r_HRU_SLP.hru & Average slope steepness $(\mathrm{m} / \mathrm{m})$ & 0 & 0.3 \\
\hline V_CH_N2.rte & Manning's $n$ value for main channel & 0 & 0.3 \\
\hline v_CH_K2.rte & $\begin{array}{l}\text { Effective hydraulic conductivity in the main channel } \\
\qquad(\mathrm{mm} / \mathrm{h})\end{array}$ & 0 & 150 \\
\hline v_SMFMX.bsn & Maximum melt rate for snow during the year $\left(\mathrm{mm} /{ }^{\circ} \mathrm{C} / \mathrm{d}\right)$ & 0 & 10 \\
\hline v_SMFMN.bsn & Minimum melt rate for snow during the year $\left(\mathrm{mm} /{ }^{\circ} \mathrm{C} / \mathrm{d}\right)$ & 0 & 10 \\
\hline V_TIMP.bsn & Snow pack temperature lag factor & 0.01 & 1 \\
\hline r_PCPMM & Average total monthly precipitation & -0.5 & 0.5 \\
\hline r_PCPSKW.wgn & Skew coefficient for daily precipitation in month & -0.5 & 0.5 \\
\hline r_PCPSTD.wgn & $\begin{array}{l}\text { Standard deviation for daily precipitation in month } \\
\qquad(\mathrm{mm} / \mathrm{d})\end{array}$ & -0.5 & 0.5 \\
\hline
\end{tabular}

In this study, due to imperfect incomplete climate data, in addition to adding CRU data to observed climate data, expert knowledge is also incorporated in the calibration period. In this process, after each calibration run the fitted parameter values 
were evaluated for each subbasin regarding the respective soil, land use, slope, and the other special characteristics of each subbasin. Then the new suitable ranges were selected for the parameters after consulting with regional experts for the next calibration period. In a conventional method, the new range of parameters for the next calibration run is determined by an optimization program (i.e. SUFI-2 in this study).

Two evaluation criteria including coefficient of determination ( $R^{2}$, Equation 1), and the Nash-Sutcliffe coefficient (NS, Equation 2) were used to evaluate the efficiency of the models developed, as follows.

$$
\begin{aligned}
& R^{2}=\frac{\left[\sum_{i}\left(Q_{m, i} \overline{Q_{m}}\right)\left(Q_{s, i} \overline{Q_{s}}\right)\right]^{2}}{\sum_{i}\left(Q_{m, i}-\overline{Q_{m}}\right)^{2} \sum_{i}\left(Q_{s, i}-\overline{Q_{s}}\right)^{2}} \\
& N S=1-\frac{\sum_{i}\left(Q_{m}-Q_{s}\right)_{i}^{2}}{\sum_{i}\left(Q_{m, i}-\overline{Q_{m}}\right)^{2}}
\end{aligned}
$$

where:

$$
\begin{aligned}
Q_{m} & =\text { observations values, } \\
Q_{s} & =\text { prediction values, } \\
m & =\text { averages of the observed values, and } \\
s & =\text { averages of the prediction values. }
\end{aligned}
$$

$R^{2}$ describes the proportion of the variance in measured data explained by the model. $R^{2}$ ranges from 0 to 1 , with higher values indicating less error variance, and typically values $>0.5$ are considered acceptable (Van Liew et al. 2003). NS indicates a normalized statistic that determines the relative magnitude of the residual variance (noise) compared to the measured data variance (information) (Nash and Sutcliffe 1970). It shows how well the plot of observed versus simulated data fits the 1:1 line. NS ranges between - and 1.0 ( 1 inclusive), with NS =1 being the optimal value. Values between 0.0 and 1.0 are generally viewed as acceptable levels of performance, whereas values $<0.0$ indicate that the mean observed value is a better predictor than the simulated value, which indicates unacceptable performance.

\section{Results and Discussion}

\subsection{Sensitivity Analysis and Model Calibration}

Sensitivity analysis results showed that all the eighteen selected parameters related to hydrology were sensitive to river discharge. Parameters such as pcpmm (average total monthly precipitation), Pcpskw (skew coefficient of daily precipitation in month) and pcpstd (standard deviation of daily precipitation in month), were the most sensitive parameters.

The calibration and validation model performance results using the SUFI-2 algorithm for the monthly discharge in the Kohnak watershed are presented in Figure 3 and Table 2. Using the observed climate data of three rain and temperature gauges as input in the SWAT model, the calibration results for the discharge station produced a poor performance as seen in Figure 3 and Table 2 (i.e. $R^{2}$ and NS values are 0.01 and -14 respectively). However the accuracy of model discharge prediction using solution methods (i.e. including CRU climate data and expert knowledge) increased significantly both in calibration and validation periods. NS and $R^{2}$ values for calibration ( 0.43 and 0.45 respectively) and validation ( 0.3 and 0.42 respectively) periods showed satisfactory prediction of river discharge by the SWAT model.
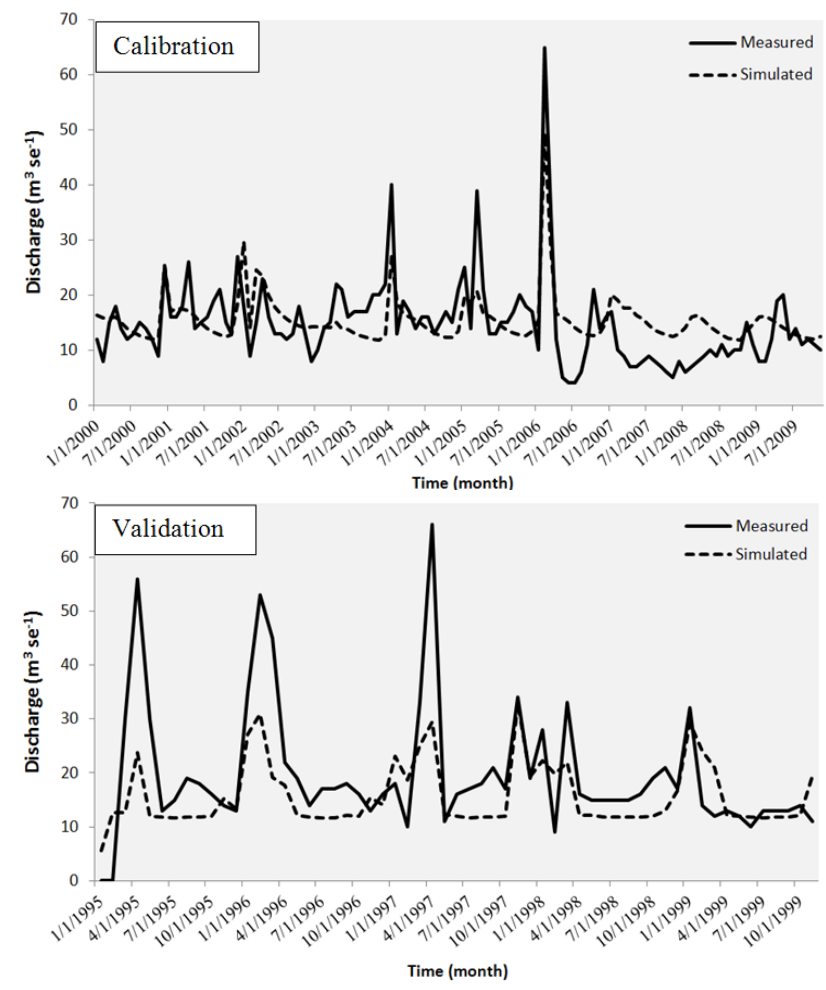

Figure 3 Comparison between the observed (solid line) and simulated (dashed line) monthly hydrographs at Kohnak outlet station for both calibration (top) and validation (bottom) periods.

Table 2 Model performance evaluation results.

\begin{tabular}{lcc}
\hline & $N S$ & $R^{2}$ \\
\hline Calibration $^{\mathrm{a}}$ & -14 & 0.01 \\
Calibration $^{\mathrm{b}}$ & 0.43 & 0.45 \\
Validation $^{\mathrm{b}}$ & 0.30 & 0.42 \\
\hline
\end{tabular}

${ }^{a}$ Calibration values using just observed climate data.

${ }^{b}$ Calibration and validation values using both solution methods: i.e. (1)observed + CRU climate data, and (2) incorporating expert knowledge in calibration period.

\subsection{Quantification of Water Resources Components}

Figure 4 shows the spatial distribution of blue water and the respective $95 \%$ uncertainty ranges for different subbasins in Kohnak watershed. The most important factor which contributes to the spatial pattern of blue water is the precipitation (Figure 5). The other factors which play roles in distribution of blue water across the watershed are land cover, soil type and topography. 
The high precipitation and the geological formation, with low permeability and steeper slopes in the northern part of the watershed, result in a relatively large amount of river discharge and thus blue water in northern and eastern subbasins of Kohnak. The $95 \%$ uncertainty ranges of average annual blue water are wider for some subbasins, which have greater precipitation, and greater blue water. The greater the blue water is (like subbasins 2,3 , and 8), the greater the uncertainty ranges are (Figure 4). $\mathrm{Xu}$ and Zuo (2014), studying blue and green water in the Wei River basin, China also reported that with increasing precipitation and blue water quantity, the uncertainty ranges increased. Faramarzi et al. (2009), estimated blue water values for the whole country of Iran using a SWAT model and reported values in two ranges $41 \mathrm{~mm} / \mathrm{y}$ to $60 \mathrm{~mm} / \mathrm{y}$ and $61 \mathrm{~mm} / \mathrm{y}$ to $200 \mathrm{~mm} / \mathrm{y}$, which are close to the simulated values in this study.
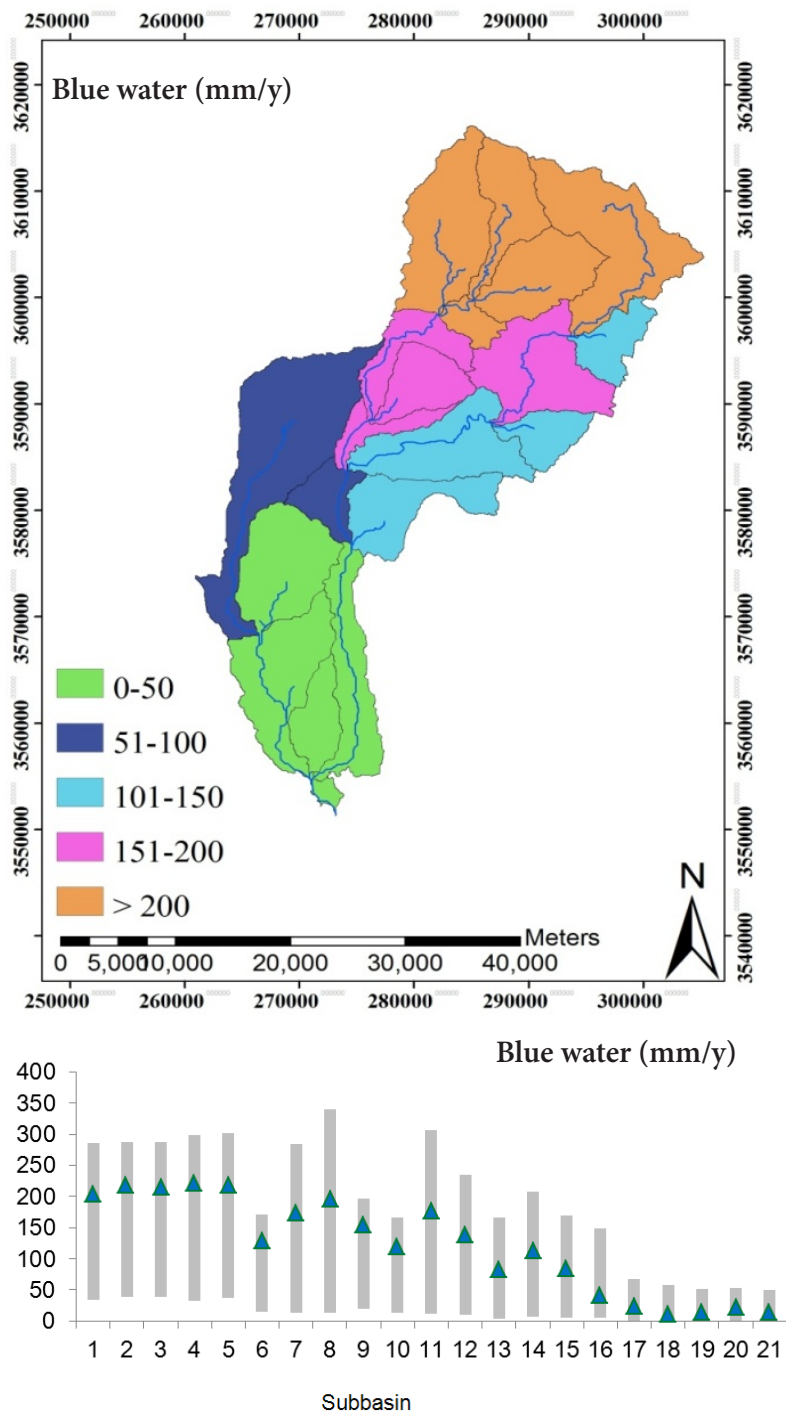

Figure 4 Spatial distribution of blue water in different subbasins of Kohnak watershed (top) and average annual simulated 95PPU ranges of the blue water flow for each subbasin (bottom).

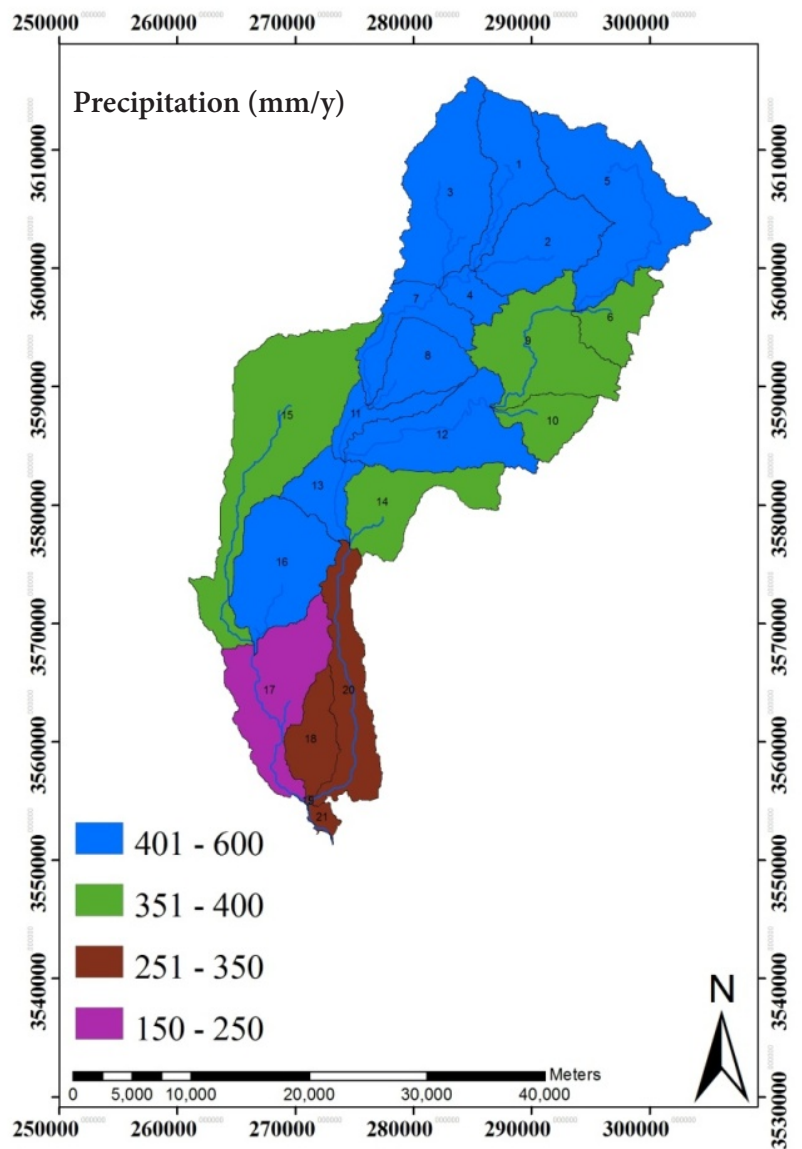

Figure 5 Spatial distribution of precipitation in different subbasins of Kohnak watershed.

The green water storage (i.e. soil moisture) simulation results are presented in Figure 6. The results showed that the green water storage increased from upstream to downstream. The highest amounts of green water storage observed in subbasins 16 and 20 in southern parts of the watershed. The green water storage in subbasin 16 showed great uncertainty, while in subbasins 8 , $5,7,1,11,3,2$ and 4 low uncertainties were estimated (Figure 6). The spatial variability of green water storage (soil moisture) is a result of soil depth, precipitation, and land cover and precipitation. In northern parts of the Kohnak watershed, despite the higher precipitation, the green water storage is lower than in the southern subbasins due to less soil depth and water infiltration which caused more blue water (i.e. surface runoff; Figure 4). The green water storage is larger in the middle and lower subbasins. It indicates that these regions have relatively sufficient precipitation and green water resources, which are beneficial for the development of rain fed agriculture.

Figure 7 shows the spatial distribution of green water flow (i.e. actual evapotranspiration) and respective $95 \%$ uncertainty ranges for different subbasins in the Kohnak watershed. The results showed that the lowest magnitude of green water flows were related to subbasins 8 and 17 with $150 \mathrm{~mm} / \mathrm{y}$ to $200 \mathrm{~mm} / \mathrm{y}$. 
The highest amount of green water flow observed in subbasin 16 ( $351 \mathrm{~mm} / \mathrm{y}$ to $400 \mathrm{~mm} / \mathrm{y}$ ). The green water flow spatial variability is a result of interactions between green water storage (i.e. soil water), land cover type, precipitation and soil depth (Xu and Zuo 2014). In addition more information on management practices can increase the accuracy of SWAT predictions (Faramarzi et al. 2009).

\section{Conclusions}

In this study the continuous semi-distributed SWAT model was successfully applied to quantify the green and blue water flows as well as the green water storage for the data scarce

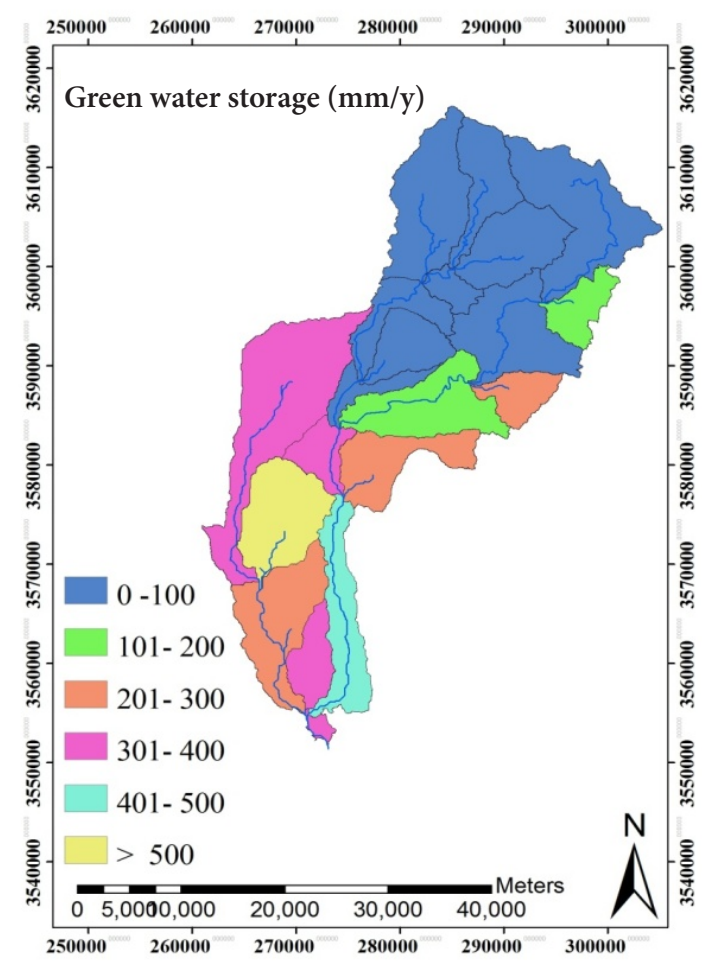

Green water storage $(\mathrm{mm} / \mathrm{y})$

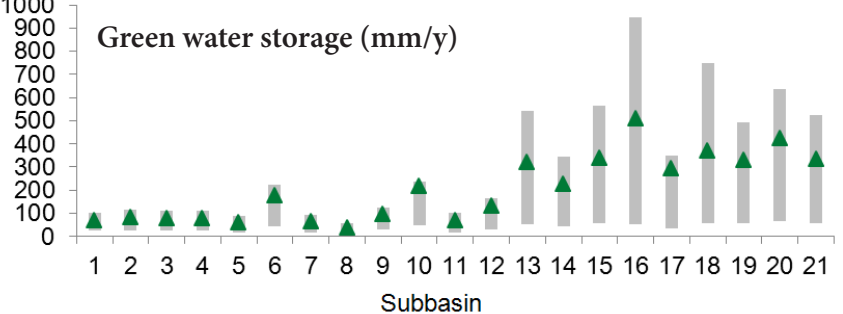

Figure 6. Spatial distribution of green water storage (i.e. soil moisture) in different subbasins of the Kohnak watershed (top) and average annual simulated 95PPU ranges of the green water storage for each subbasin (bottom).
Kohnak watershed located in the southwest of Iran. Combining CRU climate data with imperfect and incomplete local climate data, and integrating expert knowledge, for defining parameter ranges in the calibration period significantly increased the SWAT accuracy prediction for Kohnak river discharges. Calibration and validation results indicated satisfactory performance of the SWAT model in evaluating the hydrology of the watershed. The spatial distribution of blue and green water flows and green water storage were presented for the entire watershed. Generally both blue and green water flows per unit of area decreased from upstream to downstream. The results obtained from this research are valuable for efficiently utilizing and allocating the water resources and planning of cultivation system and irrigation planning in this area.
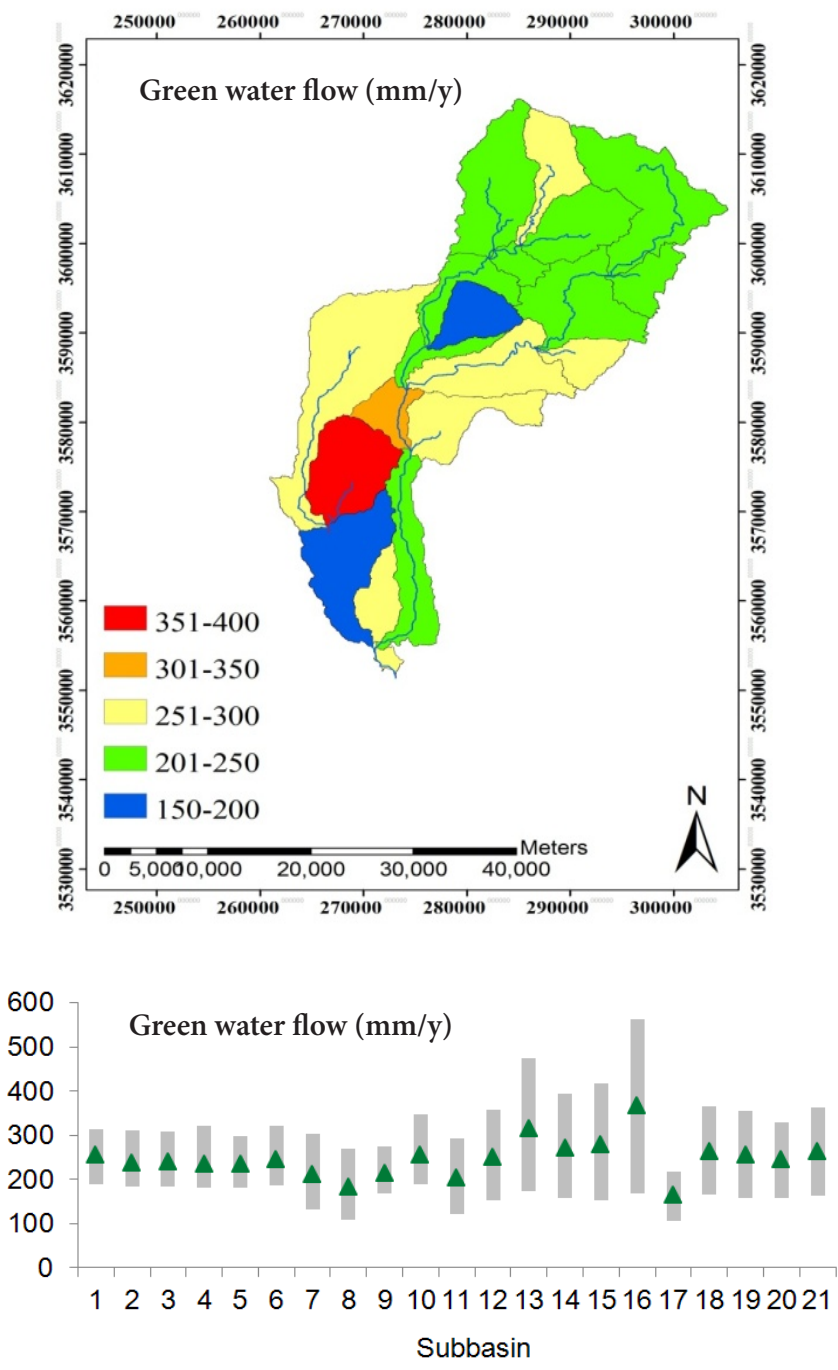

Figure 7 Spatial distribution of green water flow (i.e. actual evapotranspiration) in different subbasins of the Kohnak watershed (top) and average annual simulated 95PPU ranges of the green water flow for each subbasin (bottom). 


\section{References}

Abbaspour, K. C. 2011. Swat-Cup2: SWAT Calibration and Uncertainty Programs Manual. Version 2. Duebendorf, Switzerland: Swiss Federal Institute of Aquatic Science and Technology, EAWAG.

Abbaspour, K. C., M. Faramarzi, E. Rouholahnejad. 2010. Hydrological Modeling of Alberta using SWAT Model. Preliminary Report. Alberta: Alberta Water.

Abbaspour, K. C., E. Rouholahnejad, S. Vaghefi, R. Srinivasan, H. Yang and B. Kløve. 2015. "A Continental-Scale Hydrology and Water Quality Model for Europe: Calibration and Uncertainty of a High-Resolution Large-Scale SWAT Model." Journal of Hydrology 524:733-52.

Alizadeh, A. and A. Keshavarz. 2005. "Status of Agricultural Water Use in Iran." In Proceedings of the 2005 Iranian American Workshop on Water Conservation, Reuse, and Recycling, 94-105. Washington, DC: The National Academies Press. http://www.nap.edu/openbook.php?record_ $\mathrm{id}=11241$ \&page $=\mathrm{R} 4$

Arnold, J. G. and P. M. Allen. 1996. “Estimating Hydrologic Budgets for Three Illinois Watersheds." Journal of Hydrology 176:57-77.

Arnold, J. G., R. Srinivasan, R. S. Muttiah and J. R. Williams. 1998. "Large-Area Hydrologic Modeling and Assessment: Part I, Model Development." Journal of the American Water Resources Association 34:73-89.

Besalatpour, A., M. A. Hajabbasi, S. Ayoubi and A. Jalalian. 2012. "Identification and Prioritization of Critical Sub-Basins in a Highly Mountainous Watershed using SWAT Model." Eurasian Journal of Soil Science 1 (1): 58-63.

Bouraoui, F., S. Benabdallah, A. Jrad and G. Bidoglio. 2005. "Application of the SWAT Model on the Medjerda River Basin (Tunisia)." Physics and Chemistry of the Earth 30: 497-507.

Chow, V. T., D. R. Maidment and L. W. Mays. 1988. Applied Hydrology. New York: McGraw-Hill.

Falkenmark, M. 1995. "Coping with Water Scarcity under Rapid Population Growth." In Proceedings of the 1995 Conference of SADC Ministers, Pretoria, South Africa, 23-24 November.

Falkenmark, M. and J. Rockstrom. 2006. "The New Blue and Green Water Paradigm: Breaking New Ground for Water Resources Planning and Management." Water Resources Planning and Management 132 (3): 129-32.

Faramarzi, M., K. C. Abbaspour, R. Schulin and H. Yang. 2009. "Modeling Blue and Green Water Resources Availability in Iran." Hydrological Processes 23 (3): 486-501.

Gerten, D., H. Hoff, A. Bondeau, W. Lucht, P. Smith and S. Zaehle. 2005. "Contemporary Green Water Flows: Simulations with a Dynamic Global Vegetation and Water Balance Model." Physics and Chemistry of the Earth 30 (6-7): 334-8.

Gul, G. O. and D. Rosbjerg. 2009. "Modeling of Hydrologic Processes and Potential Response to Climate Change Through the Use of a Multisite SWAT." Water and Environment Journal 24 (1): 21-31.
Guodong, C. and Z. Wenzhi. 2006. "Green Water and Its Research Progresses." Advances in Earth Science 21 (3): 221-7.

Jackson, R. B., S. R. Carpenter, C. N. Dahm, D. M. Mcknight, R. J. Naiman, S. L. Postel and S. W. Running. 2001. "Water in a Changing World." Ecological Applications 11(4): 1027-45.

Kalogeropoulos, K. and C. Chalkias. 2012. "Modeling the Impacts of Climate Change on Surface Runoff in Small Mediterranean Catchments: Empirical Evidence from Greece." Water and Environment Journal 27 (4): 505-13.

Keshavarz, A., S. H. Ashrafi, N. Hydari, M. Pouran and E. A. Farzaneh. 2005. “Water Allocation and Pricing in Agriculture of Iran". In Proceedings of the 2005 Iranian American workshop on Water Conservation, Reuse, and Recycling, 153-72. Washington, DC: The National Academies Press. http://www.nap.edu/openbook.php?record_ id $=11241$ \&page $=$ R4

Khoi, D. N. and T. Suetsugi. 2012. “Uncertainty in Climate Change Impacts on Stream Flow in Be River Catchment, Vietnam." Water and Environment Journal 26:530-9.

Kiptala, J. K., M. L. Mul, Y. A. Mohamed and P. van der Zaag. 2014. "Modeling Stream Flow and Quantifying Blue Water Using a Modified STREAM Model for a Heterogeneous, Highly Utilized and Data-Scarce River Basin in Africa." Hydrology and Earth System Science 18: 2287-303.

Nash, J. E. and J. V. Sutcliffe. 1970. "River Flow Forecasting Through Conceptual Models. Part I, A Discussion of Principles." Journal of Hydrology 10 (3): 282-90.

Neitsch, S. L., J. G. Arnold, J. R. Kiniry and J. R. Williams. 2011. Soil and Water Assessment Tool: Theoretical Documentation: Version 2009. College Station, TX: Texas Water Resources Institute. Report Number 406.

Schuol, J., K. C. Abbaspour, H. Yang, R. Srinivasan and A. J. B. Zehnder. 2008. "Modeling Blue and Green Water Availability in Africa." Water Resources Research 44:W0740. doi: 10.1029/2007WR006609.

USDA-SCS (U.S. Department of Agriculture, Soil Conservation Service). 1972. National Engineering Handbook, Hydrology, sec 4, ch. 4-10. Washington, DC: U. S. Departmentof Agriculture.

Van Liew, M. W., J. G. Arnold and J. D. Garbrecht. 2003. “Hydrologic Simulation on Agricultural Watersheds: Choosing Between Two Models." Transactions of the ASABE 46 (6): 1539-51. doi:10.13031/2013.15643.

Xu, Z. and D. Zuo. 2014. "Simulation of Blue and Green Water Resources in the Wei River Basin, China." In IAHS-EGU 6: Proceedings of the 2014 6th IAHS-EGU International Symposium on Integrated Water Resources Management, 81-2. Bologna. http://distart1 19.ing.unibo.it/bo2014/Book_Abstract.pdf

Zang, C., J. Liu, L. Jiang and D. Gerten. 2013. "Impacts of Human Activities and Climate Variability on Green and Blue Water Flows in the Heihe River Basin in Northwest China." Hydrology and Earth System Science 10:9477-504. 